\title{
Dynamic Simulation of Bio-Hydrogen System Driven Waste Heat from Steel-Manufacturing Process
}

\author{
Joon Ahn', Hyejun Kim \\ ${ }^{1}$ School of Mechanical Engineering, Kookmin University \\ 02707 Seoul, Korea \\ jahn@kookmin.ac.kr
}

\begin{abstract}
In this study, we proposed a bio-hydrogen system using waste heat and by-product gas from steelworks. Dynamic simulations were carried out for the system using intermittent skirt cooling water as the heat source. The temperature changes in the components over time were compared with the measured data. The simulation results showed that the trend of temperature variation with time of each component was well predicted. Experiments and simulations agreed well not only with the design conditions but also with two off-design conditions. After confirming the reliability, we designed a 10-ton reactor for installation in the actual site using simulations. Simulation results showed that the minimum volume of the system was determined such that the effectiveness of the heat storage tank and minimum variation in the temperature of the reactor were ensured.
\end{abstract}

Keywords: Bio-hydrogen, Heat exchanger, Thermal design.

\section{Introduction}

Hydrogen production technologies developed so far include gasification of biomass, electrolysis of water, photochemical methods, biological methods, etc. Of these, biological methods are mainly the production of hydrogen using microorganisms. It is economically feasible and expected to be a sustainable system, but effective microorganisms should be found and the system should be optimized [1].

Korea explored deep-sea hydrothermal parts, found microorganisms that produce hydrogen by consuming carbon monoxide and water during metabolism, and published it under the name NA1. As a result of examining the hydrogen production according to the culturing conditions of the strain NA1, the highest productivity was obtained at $80^{\circ} \mathrm{C}$, which is close to the environment in which the first strain was harvested. The reactor temperature should be maintained at $80{ }^{\circ} \mathrm{C}$ and carbon monoxide should be supplied. Therefore, a steel mill in which waste heat and CO are generated as byproduct gas is proposed as an economical bio-hydrogen production site [2].

The biohydrogen process does not require high purity $\mathrm{CO}$, so it is analyzed that it is effective to utilize the unused portion of LDG (Linze Dnawitz Gas) as substrate gas. Skirt cooling water has not been actively used since it occurs only for 15 minutes in a 40 minute cycle. The cooling water was discharged at $98^{\circ} \mathrm{C}$ and supplied to $70^{\circ} \mathrm{C}$ after air cooling or heat exchange, and tens of tons per hour was used, which was considered to be suitable as a heat source for the biohydrogen system [3].

In this study, 1/10 scale experiment was conducted and the response characteristics of the reactor, the heat storage tank, and the feed mixing tank (FMT) to the intermittent heat source were obtained through simulation. Based on the validation results, a simulation of a 10-ton reactor to be installed in a pilot plant was carried out. The number of plates of the heat exchanger, the size of the reactor and the size of the heat storage tank were selected as the parameters for the optimization of the 10-ton reactor, and the simulation was performed until the temperature deviation started to increase, where the volume of the heat exchanger was calculated. 


\section{Experimental setup and simulation technique}

(a)

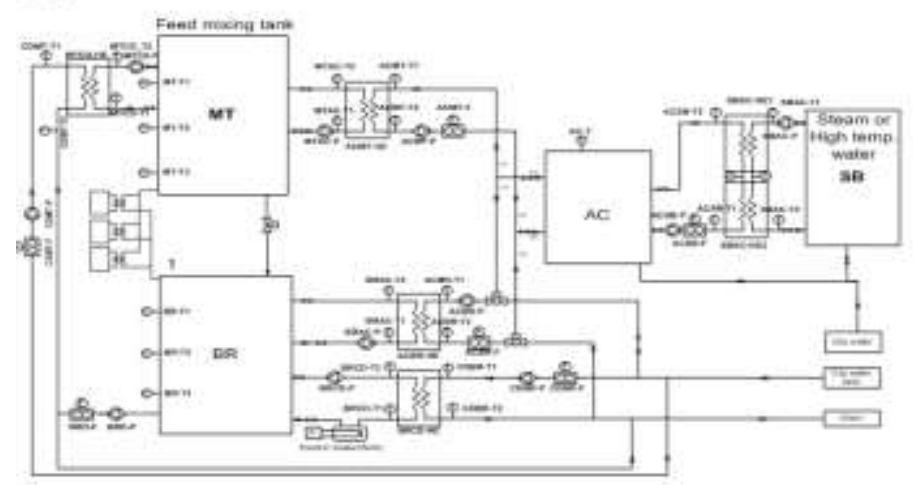

(b)

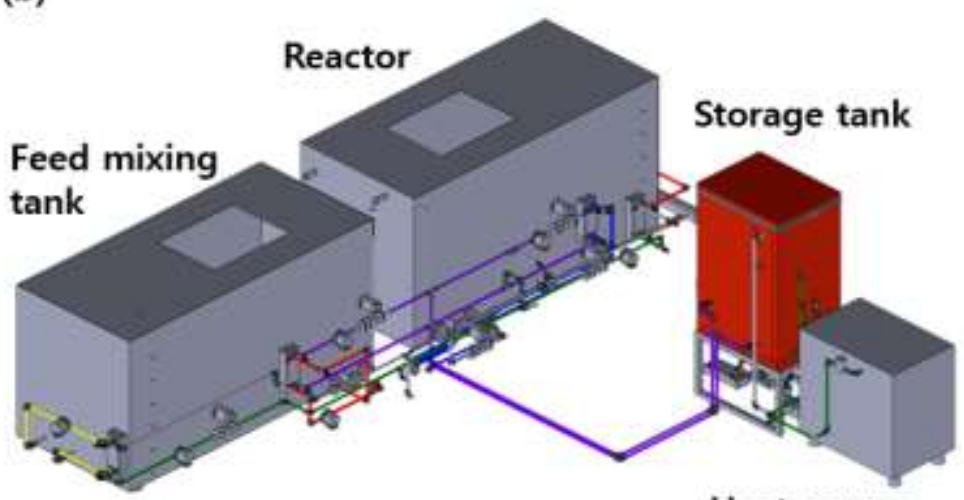

Heat source

Fig. 1: Bio-hydrogen production system simulator; (a) piping and instrumentation diagram; (b) 3-D drawing.

The simulator of the biohydrogen production system tested in the study is shown in Fig. 1 . Hot water at $95^{\circ} \mathrm{C}$ was supplied as a heat source, and a heat storage tank was placed in the middle to smooth the temperature in the reactor. FMT, which mixes yeast, saline and the like to make a medium, was also connected to the reactor. The reactor, the heat storage tank, and the FMT were able to change the volume by adjusting the floor height to observe the effect of the capacity.

The experimental system operates with a 40 minute cycle reflecting the characteristics of the LDG process and the system provides a $95^{\circ} \mathrm{C}$ hot water for 15 minutes in a 40 minute cycle, so the system has a waste heat pattern with a periodic rise and fall in temperature. The control system was designed to maintain the temperature of the initial storage tank, reactor, and water supply tank after one cycle. During the experiment, the temperature inside the reactor, the heat storage tank and the FMT was measured with a platinum resistance thermometer (RTD: Pt100, KORINS) and data were acquired DAQ every second.

The simulation was carried out using Matlab 2016b and the changes in density, viscosity, thermal conductivity were taken into account. The reactor temperature changes according to the size of the heat storage tank were simulated and compared with the experimental results. In the simulation process, the size of the heat exchanger, the heat storage tank and the water supply tank, the target temperature, the outside temperature, and the simulation time are input. Thus, heat of bioreactor, sensible heat, and ambient heat radiation are calculated and the load of each element is determined.

The system temperature is different from the target temperature due to the difference between the heat transfer rate and the load. This is controlled by adjusting the mass flow rate on the heat source side while keeping the target side mass flow rate of the heat exchanger constant. The variation of the mass flow rate is proportionally controlled by the difference between the load in the reactor and the heat transferred through the heat exchanger. This controls the temperature of the reactor and feedwater mixer.

\section{Results and disussion}

The simulation results are compared with the experimental results using the same conditions as the design conditions of the simulator (1 ton volume, $300 \mathrm{~kg}$ storage tank, $125 \mathrm{mmol} / \mathrm{L} / \mathrm{hr}$ based on NA1 hydrogen production) and presented in Fig. 2. It can be seen that the temperature variation amplitude level and trend are well predicted by simulation in the heat storage tank (Fig. 2(a)), FMT (Fig. 2(b)) and reactor (Fig. 2(c)). In the early stage of operation, the temperature is expected to be slightly lower than that of the experiment in the storage tank and reactor due to the difference of the initial conditions. However, after 5 hours (after 20000 seconds), the experimental results are accurately reproduced by the simulation. 
(a)

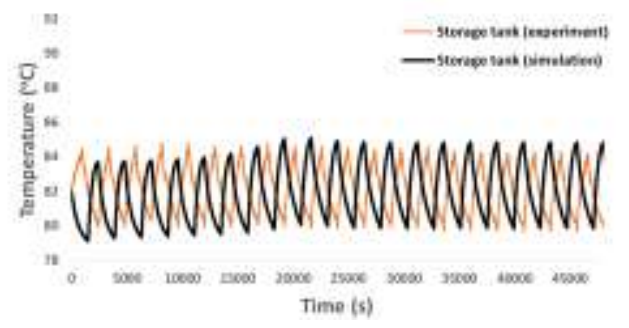

(b)

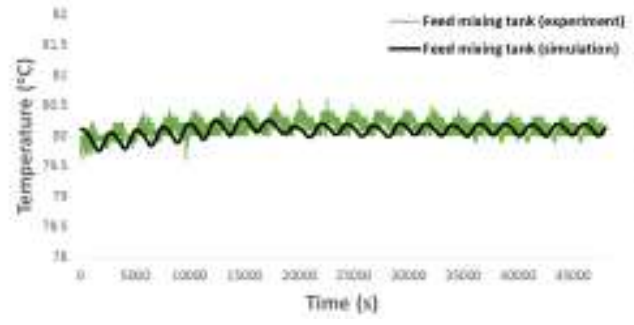

(c)

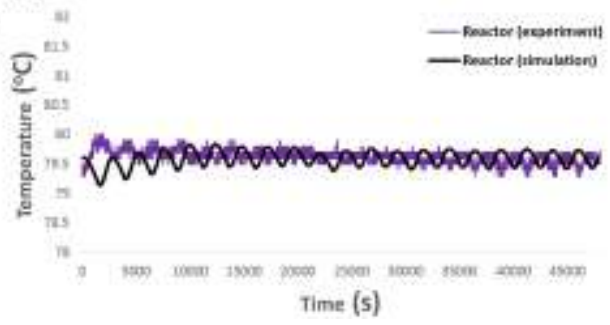

Fig. 2: Temporal change of the temperature of system components at the design condition (300 kg storage tank, $125 \mathrm{mmol} / \mathrm{L} / \mathrm{hr} \mathrm{H}_{2}$ production); (a) Storage tank; (b) Feed mixing tank; (c) Reactor.

(a)

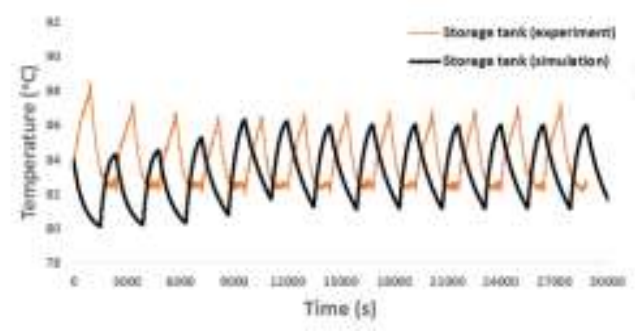

(b)

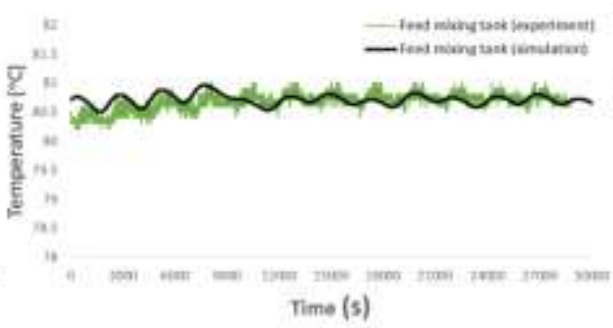

(c)

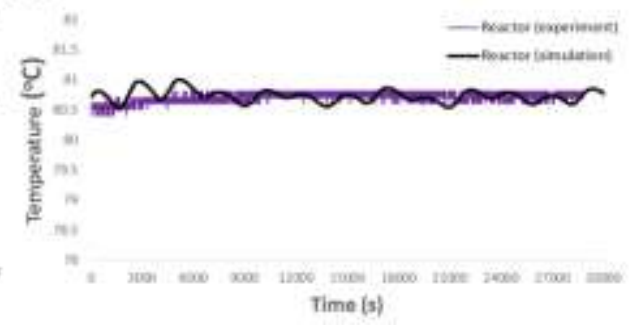

Fig. 3: Temporal change of the temperature of system components for $250 \mathrm{mmol} / \mathrm{L} / \mathrm{hr} \mathrm{H}_{2}$ production; (a) Storage tank; (b) Feed mixing tank; (c) Reactor.

The project aims to increase the reaction coefficient by promoting the mixing in the reactor. The simulation results are shown in Fig. 3. Even when the hydrogen production was increased to $250 \mathrm{mmol} / \mathrm{L} / \mathrm{hr}$, the temperature distribution of each element was well predicted by simulation, but slight difference was observed in the storage tank (Fig. 3(a)).

The cause of the discrepancy may be that the RTD has a finite response rate to the temperature change. In the case of the heat exchanger, dynamic response characteristics are considered according to the heat capacity, but in the case of the pump, it is considered that the error is generated by performing the simulation assuming the flow rate as a step function. Compared with the design conditions, it is possible that the flow rate is increased and the local temperature deviation is generated when the hydrogen production is doubled.

(a)

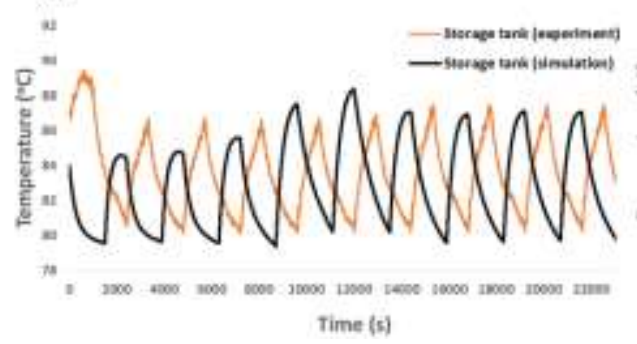

(b)

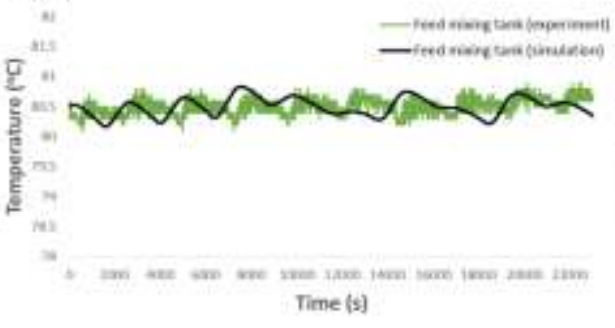

(c)

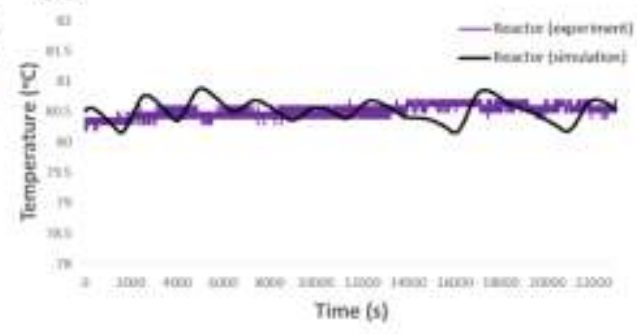

Fig. 4: Temporal change of the temperature of system components for $125 \mathrm{~kg}$ storage; (a) Storage tank; (b) Feed mixing tank; (c) Reactor.

Next, the temperature of the hot water supplied to the reactor can be maintained at $80^{\circ} \mathrm{C}$ or higher even if the capacity of the heat storage tank is reduced to half [3]. If the capacity of the heat storage tank is reduced to half (Volume 1 ton, heat storage tank $150 \mathrm{~kg}$, NA1 hydrogen production of $250 \mathrm{mmol} / \mathrm{L} / \mathrm{hr}$ ). The temperature changes of the thermal storage tank, FMT, and reactor obtained by simulation are compared with experimental results in Fig. 4. In this case as well, it can be seen 
that the test results are well predicted by the simulation as a whole. In the heat storage tank, experimental values and simulations differ slightly in the initial section due to differences in the initial conditions, but they agree well after 3 (Fig. 4(a)). In the case of reactor and FMT, the temperature change was well predicted by simulation.

So far, the reliability of the simulation has been verified by comparing the results of experiments with simulations of 1 ton hydrogen production reactor simulator. Based on this, a simulation was conducted for designing a 10-ton reactor to be installed at the actual steelworks site. The parameters for the design of the 10-ton reactor were selected as the number of plates of the heat exchanger, the size of the reactor, and the size of the heat storage tank. The size of each device was selected as a reference point of 10 times the size of the 1-ton simulator. In the heat exchanger, the number of plates was 25, the heat storage tank was $2500 \mathrm{~kg}$, and the reactor was $10000 \mathrm{~kg}$. Using this as a reference point, the simulation was carried out in such a way that the size can be reduced while maintaining the temperature deviation.

(a)

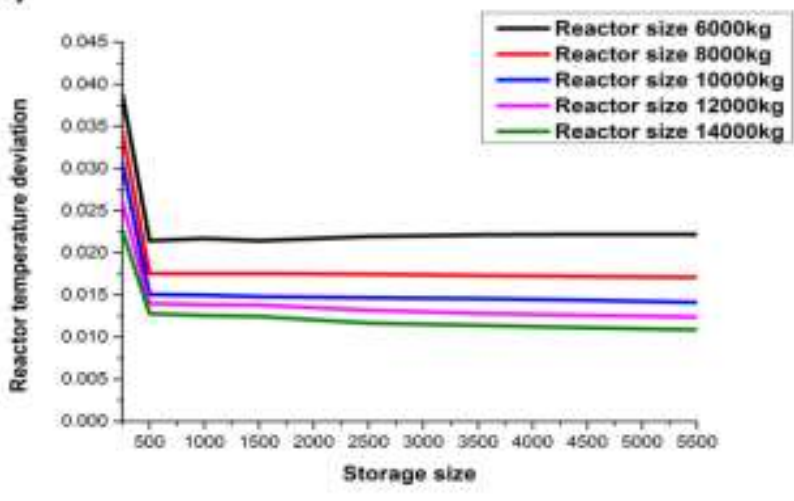

(b)

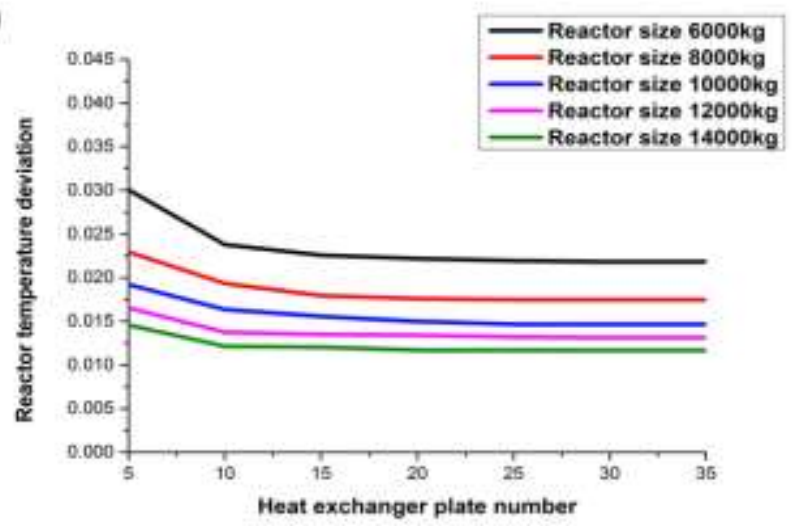

Fig. 5: Temperature deviation at the 10 ton class reactor; (a) For different storage tank size; (b) For different number of plates of the heat exchanger.

Fig. 5 shows the simulation results. Simulation results show that the largest influences on the temperature variation of the reactor are the reactor size, the size of the heat storage tank, and the number of heat exchanger plates. However, the size of reactor and the number of heat exchanger plates were adjusted because the size of reactor was fixed variable when hydrogen production rate and reaction rate were fixed. When the size is reduced, the point where the temperature deviation increases becomes the minimum size and the simulation is performed.

Through preliminary simulation, it was confirmed that the size of the heat storage tank did not affect the temperature deviation from $2500 \mathrm{~kg}$. Therefore, the simulation was performed up to $250 \mathrm{~kg}$ less than $2500 \mathrm{~kg}$. In Fig. $5(\mathrm{a})$, it can be seen that the temperature deviation of the reactor is not controlled but is high at a size of $500 \mathrm{~kg}$ or less. This is because the temperature of the heat storage tank falls below the target temperature of the reactor of $80^{\circ} \mathrm{C}$ and does not serve as a heat storage tank for supplying heat. Therefore, this point can be specified as the minimum size of the storage tank.

From the same viewpoint, it can be seen in Fig. 5(b) that the temperature uniformity of the reactor is increased because the heat required by the reactor and the feed mixing tank can not be transferred from the heat storage tank when the number of the heat exchanger plates is 10 or less. Therefore, the size of the heat exchanger was predicted to be the minimum number of plates required when using Danfoss' plate type heat exchanger XB 06H-1-26-H.

If the number of plates in a plate heat exchanger is 10 , it is judged to be reasonable if the pressure drop condition is satisfied. The number of minimum plates will increase if you use a plate smaller than the one you used to perform the analysis. In the current design, the pressure drop is not taken into account as a separate condition, but if a restriction is set and the current system causes an excessive pressure drop, the number of plates will increase.

\section{Conclusions}

(1) Comparison of simulations with 1 ton class reactor simulator confirmed that temperature variation characteristics of each component are well predicted. 
(2) Experiments and simulations agree well with the design conditions as well as the two off-design conditions, and it is considered that the simulation can be applied to the design of 10 ton class reactor.

(3) Based on the simulation, we have found the minimum volume of the system that guarantees the heat source effectiveness of the heat storage tank and the minimum temperature deviation of the reactor.

\section{References}

[1] I. Dincer, and C. Acar, "Review and Evaluation of Hydrogen Production Methods for Better Sustainability," Int. J. Hydrogen Energy, vol. 40, pp. 11094 11111, 2015.

[2] S. Rittmann, H. S. Lee, J. K. Lim, T. W. Kim, J. H. Lee and S. G. Kang, "One-Carbon Substrate-based Biohydrogen Production: Microbes, Mechanism, and Productivity," Biotechnol. Adv., vol. 33, pp. 165 177, 2015.

[3] H. Kim, S. Kim and J. Ahn, "Dynamic Thermal Design of a 1-ton Class Bio-hydrogen Production System Simulator Using Industrial Waste Heat and By-products," Korean J. Air-Cond. Refrig. Eng., vol. 29, pp. 259 268, 2017. 